\title{
Assembling Nonplanar Polyaromatic Units by Click Chemis- try. Study of Multicorannulene Systems as Host for Fullerenes
}

\author{
Celedonio M. Álvarez ${ }^{*}$, , Gabriel Aullón ${ }^{\star}$, Héctor Barbero ${ }^{\dagger}$, Luis A. García-Escudero ${ }^{\dagger}$, Cristina Martí- \\ nez-Pérez ${ }^{\dagger}$, Jose M. Martín-Álvarez ${ }^{\dagger}$, Daniel Miguel ${ }^{\dagger}$ \\ †'GIR MIOMeT, IU CINQUIMA/Química Inorgánica, Facultad de Ciencias, Universidad de Valladolid, E-47005, Valladolid, \\ Spain \\ "Departament de Química Inorgànica, Facultat de Química, Universitat de Barcelona, Martí i Franquès 1-11, E-08028 Barce- \\ lona, Spain
}

Supporting Information Placeholder
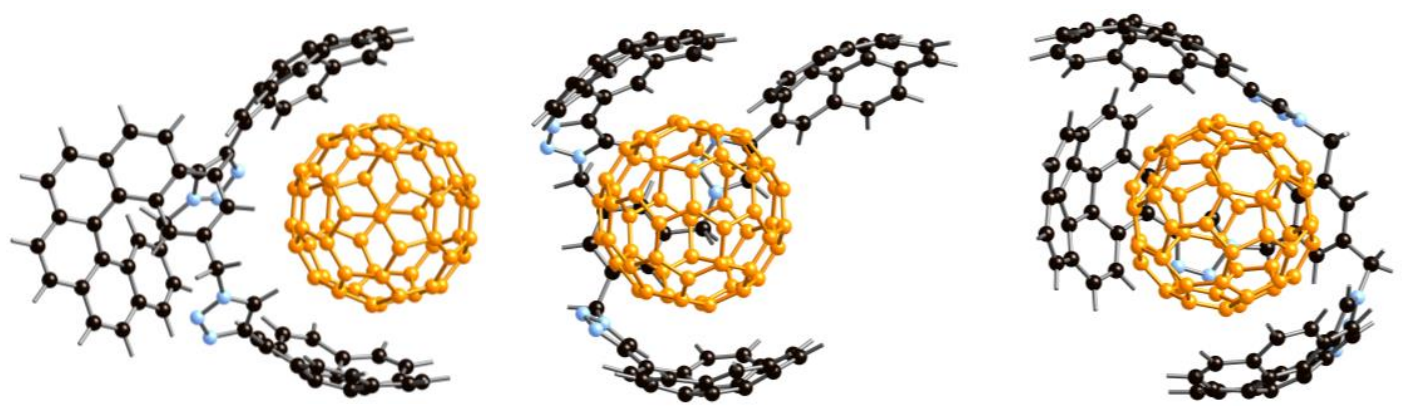

\begin{abstract}
Novel compounds with two or three corannulene subunits have been obtained by "Click Chemistry". These exotic systems were synthesized in high yields using the ethynylcorannulene as common reagent. The synergistic action as receptors for fullerenes of several corannulene blocks has been evaluated. It was found that the three-armed derivatives showed efficient complexation abilities toward $\mathrm{C}_{60}$. Furthermore, a new compound having two corannulene subunits linked to a hexahelicene scaffold, has a remarkable affinity constant. Finally, theoretical calculations have been performed to evaluate the formation of their relative adducts containing a $\mathrm{C}_{60}$ molecule.
\end{abstract}

Corannulene is a non-planar polyaromatic molecule which can be considered a fragment of fullerene $\mathrm{C}_{60} \cdot{ }^{1}$ This bowl shaped $\pi$-conjugated compound has several interesting properties. ${ }^{2}$ Its non-planar shape gives rise to stronger interactions with fullerenes. In the first place, corannulene has a dipole moment due to the different electronic density on its concave and convex faces, ${ }^{3}$ which allows the existence of dipolar interactions. On the other hand, there is an excellent complementarity between the concave inner surface of corannulene and the outer convex surface of fullerene that has recently been displayed by a 1:1 cocrystallization between both molecules. ${ }^{4}$ These properties of the bowl-shaped corannulene have promoted the study of several corannulene derivatives as hosts for fullerenes, ${ }^{5}$ including polymeric architectures. ${ }^{6}$ Our previous work studied the preparation of bis-arene(acetylide) platinum complexes of several polycyclic aromatic hidrocarbons (PAHs) such as pyrene, helicene or corannulene; evidence that the corannulene derivative showed the most efficient association with fullerenes out of all the platinum complexes (Figure 1, left). ${ }^{7}$ These biscorannulene tweezers present a strong $\pi-\pi$ interaction with the fullerene. This effect had been previously found by Sygula et al. for their all-organic buckycatcher containing two corannulene units (Figure 1, right top). ${ }^{5 \mathrm{~d}, \mathrm{e}, \mathrm{g}, \mathrm{h}}$
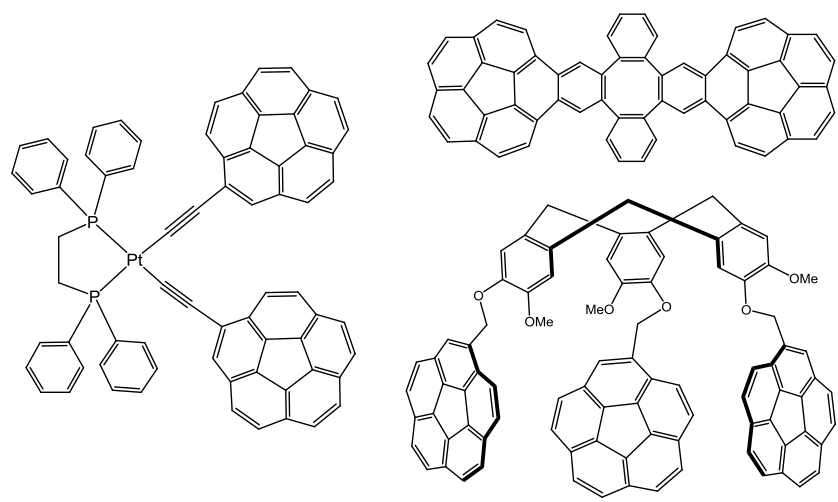

Figure 1. Previously reported multi-corannulene hosts for fullerene.

It is reasonable to think that an adequate strategy to obtain improved corannulene-based receptors for fullerenes would be to increase the number of corannulene units in the host, where two or more corannulene moieties can interact with fullerenes simultaneously. Along this line, Sygula et al. reported a triscorannulene compound with a cyclotriveratrylene tether (Figure 1 , right bottom $)^{5 f}$ concluding that having three corannulene 
subunits did not substantially improve the affinity for fullerenes, despite the great results observed previously by Mendoza et $a .^{8}{ }^{8}$ with exTTF receptors. Although the compound seems to accommodate well for a $\mathrm{C}_{60}$ inclusion, the thermodynamic data arising from experimental NMR titration suggested that only two corannulenes interacts with guest molecule. Additionaly, it was hypothesized that the intrinsic flexibility of the host could make stacked conformers competing with the formation of inclusion complexes. Under these limitations, we considered to evaluate the affinity of other multi-corannulene hosts having similar flexibility but modifying the geometry of the tether in order to reduce them.

Herein, we present the synthesis and complexation study with $\mathrm{C}_{60}$ of two three-armed triscorannulene derivatives (1 and 2). Additionally, we have designed and prepared a novel biscorannulene compound $\mathbf{3}$, in which two corannulene subunits are linked to a chiral hexahelicene skeleton through triazole units.

We used copper catalyzed azide-alkyne cycloaddition $(\mathrm{Cu}$ AAC) as a simple and practical route to prepare these compounds. Known as "click chemistry", this regioselective procedure has been used in recent years for the preparation of a wide variety of new materials. ${ }^{9}$ Parallel to our work, Stuparu published the synthesis of triazole-linked corannulene derivatives using $\mathrm{CuAAC}$ as an efficient synthetic route to prepare related corannulene rich materials. ${ }^{10}$

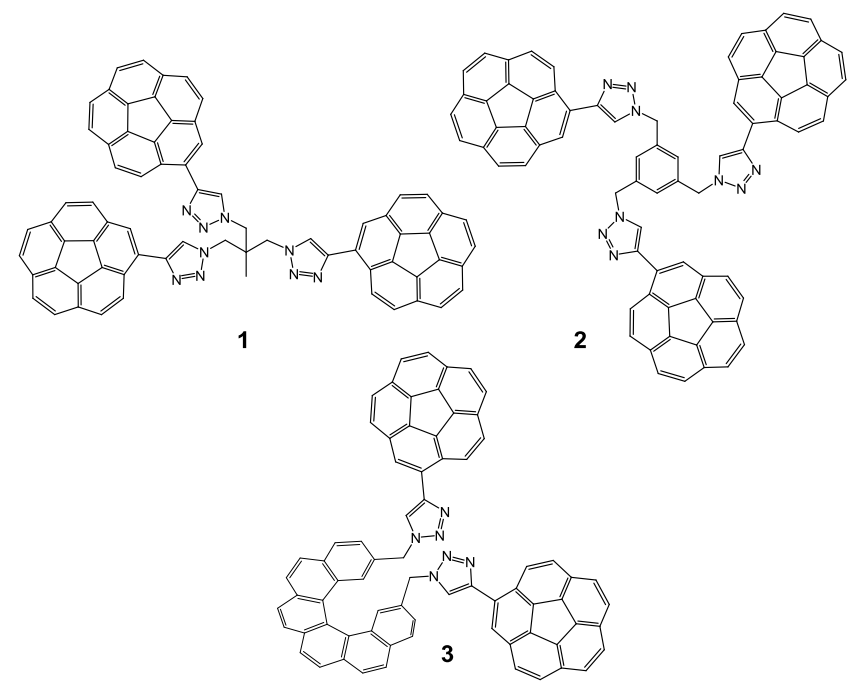

Figure 2. Structure of corannulene derivatives $\mathbf{1}$ to $\mathbf{3}$.

The preparation of all new compounds started from ethynylcorannulene as common alkyne reagent (4). ${ }^{11}$ Two known azides, $\alpha, \alpha, \alpha$-tris(azidomethyl)ethane (5) and 1,3,5-tris(azidomethylbencene) (6), were prepared by using a reported procedure, ${ }^{12}$ while a third one was synthesized following the protocol depicted in Scheme 1, in which 2,15-dimethylhexahelicene $(7)^{13}$ was monobrominated on each methyl group before nucleophilic substitution with an excess of sodium azide to give $\mathbf{9}$ in good yields.

Scheme 1. Synthesis of 2,15-bis(azidomethyl)hexahelicene (9).

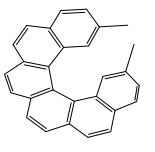

7

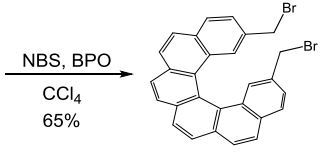

8

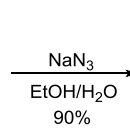

$90 \%$

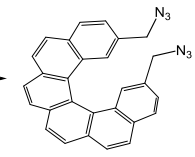

9
The three azides react with ethynylcorannulene, in the presence of catalytic amounts of copper sulfate and sodium ascor- bate in a mixture of $4: 1 \mathrm{THF} / \mathrm{H}_{2} \mathrm{O}$ to afford, in good yields, the expected 1,4-disubstituided 1,2,3-triazoles $\mathbf{1 - 3}$, respectively (see Supporting Information for experimental details). The new corannulene compounds have been completely characterized by analytical and spectroscopic methods.

${ }^{1} \mathrm{H}-\mathrm{NMR}$ spectrum recorded in $\mathrm{CD}_{2} \mathrm{Cl}_{2}$ for triscorannulene derivative 1 shows the presence of a single compound of high symmetry. The protons of the three corannulene subunits appear as chemically equivalent and show a pattern consisting of a doublet at $8.38 \mathrm{ppm}$ (integrating to $3 \mathrm{H}$ ), a singlet at 8.29 ppm $(3 \mathrm{H})$ and a multiplet of overlapped signals between 7.82$7.70(21 \mathrm{H})$; while the signal of the triazole appears at 8.64 ppm as a singlet. In addition, the signals of the aliphatic protons appear at $4.71 \mathrm{ppm}$ as singlet (methylene protons) and at $1.16 \mathrm{ppm}$ as singlet (methyl group). These data are in agreement with the proposed structure bearing three corannulene units in the molecule. ${ }^{1} \mathrm{H}-{ }^{1} \mathrm{H}$ NOESY spectrum of $\mathbf{1}$ in $\mathrm{CD}_{2} \mathrm{Cl}_{2}$ showed a NOE cross peak between the triazole and the methylene protons (see Figure S9). However, a NOE cross peak between the triazole and the methyl group was not observed. All these results suggest that compound 1 keep a $C_{3}$ axis in solution, being the triazole protons and the methyl group in a relative anti orientation. Moreover, its ${ }^{13} \mathrm{C}\left\{{ }^{1} \mathrm{H}\right\}$ NMR spectrum agree to this highly symmetrical structure.

Regarding compound 2 , the ${ }^{1} \mathrm{H}$ NMR spectral pattern at room temperature suggests that this molecule, again, has a high degree of symmetry in solution. The corannulene protons in $\mathbf{2}$ show a characteristic signal pattern in the aromatic region consisting of one singlet, three pairs of doublets and two $\mathrm{AB}$ systems in the region of 8.1-7.2 ppm. Additionally, two extra singlet peaks at 7.94 and $7.28 \mathrm{ppm}$ can be assigned to triazole and benzene rings, respectively. The remaining methylene protons appear at $5.54 \mathrm{ppm}$ as a singlet. These results, together with its ${ }^{13} \mathrm{C}\left\{{ }^{1} \mathrm{H}\right\}$ NMR and $2 \mathrm{D}$ spectra, unambiguously support the trigonal structure depicted in Figure 2 for this derivative.

Finally, compound 3 shows a very crowded ${ }^{1} \mathrm{H}$ NMR spectrum in the aromatic region in $\mathrm{CDCl}_{3}$ (see Figure S20). Thirty corannulene or helicene protons appear in the region of 8.2-7.6 ppm as doublets, $\mathrm{AB}$ systems or singlets, making very difficult the assignment of all the signals. The triazole singlet appears at $7.27 \mathrm{ppm}$, partially hidden by the solvent residual peak, and the remaining aromatic signal corresponding to two helicene protons are around $7.16 \mathrm{ppm}$. The diasterotopic protons of methylene appear as a pair of doublets at $\delta 5.17$ and $4.89 \mathrm{ppm}$. ${ }^{1} \mathrm{H},{ }^{13} \mathrm{C}\left\{{ }^{1} \mathrm{H}\right\}, 2 \mathrm{D}$ NMR spectral data, along with Mass Spectrum, are in agreement with the presence of two corannulene moieties in the molecule.

Once characterized the identity of all compounds, several experiments were carried out in order to determine the binding constant with $\mathrm{C}_{60}$. A deuterated toluene solution of either receptor was titrated with fullerene and a Job's plot was plotted for each compound at room temperature. All of them are consistent with the formation of 1:1 stoichiometry adducts.

For compound 1, the NMR titration experiment showed that, surprisingly, the most significant changes in chemical shift were observed for methylene protons (see Figure 3). Although the concave surfaces of corannulene subunits should wrap nicely around the entrapped fullerene guest, this data suggests that the position of fullerene within our host is very close to the $\mathrm{CH}_{2}$ fragment. This behavior could be explained by the formation of reasonable $\mathrm{CH}-\pi$ interactions between the methylene groups and $\mathrm{C}_{60}$. In fact, there are some examples about 
the existence of these interactions in supramolecular fullerene chemistry. $^{14}$

The binding constants $\left(\mathbf{K}_{\mathbf{a}}\right)$ of complexes $\mathbf{1} \subset \mathbf{C}_{\mathbf{6 0}}, \mathbf{2} \subset \mathbf{C}_{\mathbf{6 0}}$ and $\mathbf{3}^{3} \mathbf{C}_{\mathbf{6 0}}$ in toluene- $\mathrm{d}_{8}$ at room temperature were found to be $(2.15 \pm 0.30) \times 10^{3},(2.19 \pm 0.05) \times 10^{3}$ and $(2.55 \pm 0.14) \times 10^{3} \mathrm{M}^{-1}$ respectively. These values are among the highest reported to date for a corannulene derivative as a host for fullerenes, however, it's very interesting, and not totally surprising, to notice that all measured constants are of the same order, independently from the number of corannulene subunits. This fact can be explained a priori by the existence of intra and/or intermolecular interactions between corannulene units, which are known to induce notable changes in its properties. ${ }^{15}$

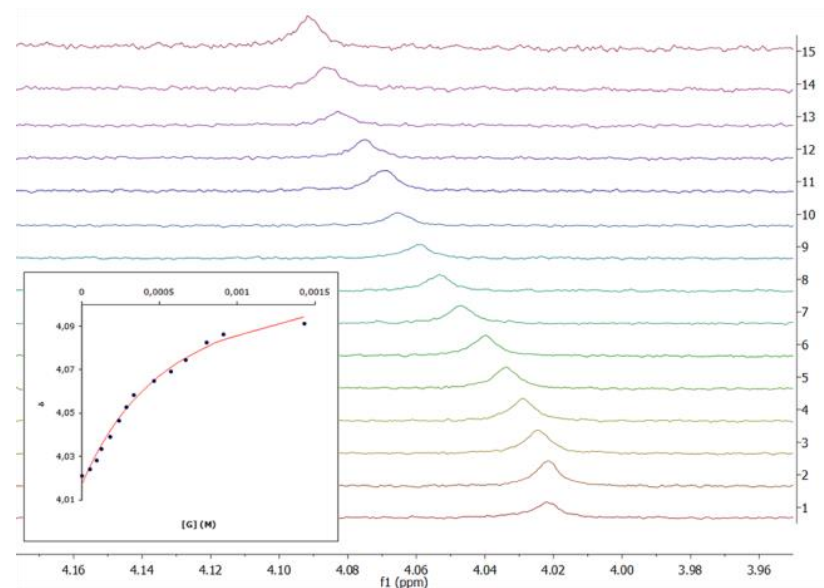

Figure 3. Methylene region of ${ }^{1} \mathrm{H}$ NMR spectra of a dilute toluene- $\mathrm{d}_{8}$ solution of $\mathbf{1}\left(2.0 \times 10^{-4} \mathrm{M}\right)$ with variable concentration of $\mathrm{C}_{60}$. Nonlinear curve regression for the results of the titration for methylene proton (inset, bottom left).

The possible self-association of compounds 1-3 has been studied by ${ }^{1} \mathrm{H}-\mathrm{NMR}$ spectroscopy using the analysis of proton chemical shifts in toluene- $\mathrm{d}_{8}$ solution as a function of concentration. In all cases, the signals of all protons remain unchanged, evidencing the lack of self-association in the derivatives 1-3. However, intramolecular association may still occur and affect the value of the measured binding constants, therefore, theoretical calculations were performed to evaluate their strength. ${ }^{16}$

Taking into account the preliminary computational results discussed in the supplementary data, several conformations for compounds 1-3 were optimized. For the host 3, the most stable structure has both corannulene subunits in a concave-concave situation, as in Figure 4, left, being able to reasonably accommodate a $\mathrm{C}_{60}$ just by slightly opening the tweezers. A second 'onion-like' conformer, very close in energy (less than 1 $\mathrm{kcal} / \mathrm{mol}$ ) was found, with the corannulene moieties pointing in near perpendicular directions and the helicene spacer between them, most likely having $\mathrm{CH}-\pi$ interactions, as in Figure 4 , right.

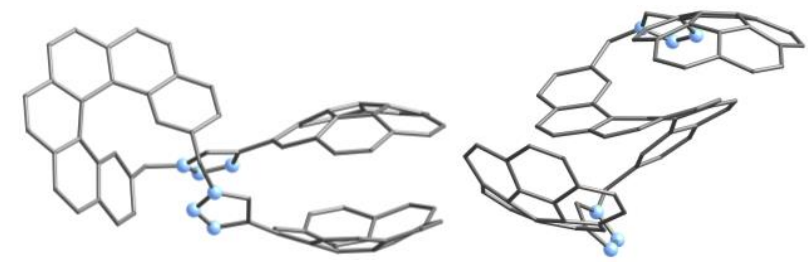

Figure 4. Optimized geometry for the most stable hosts. Hydrogen atoms are omitted for clarity.
Since the first conformer is well preorganized to act as a host to fullerenes, this adduct was reoptimized in the presence of a $\mathrm{C}_{60}$. The expected adduct, namely $\mathbf{3} \subset \mathbf{C}_{60}$ in Figure 5 (right), shows the two corannulenes interacting properly with the fullerene. The same protocol was applied for host $\mathbf{2}$, in which two minima for $\mathbf{2} \subset \mathbf{C}_{\mathbf{6 0}}$ were found. In both cases just two corannulenes can be considered to interact satisfactorily with the fullerene, and the third subunit seems not to be able to adapt to the remaining surface of the geodesic polyarene or it prefers to establish interactions with one of these former corannulenes (Figure 5, left). This conformer is $12.2 \mathrm{kcal} / \mathrm{mol}$ more stable than the other and will be discussed next, the results for the less stable conformer are included in the supplementary data.
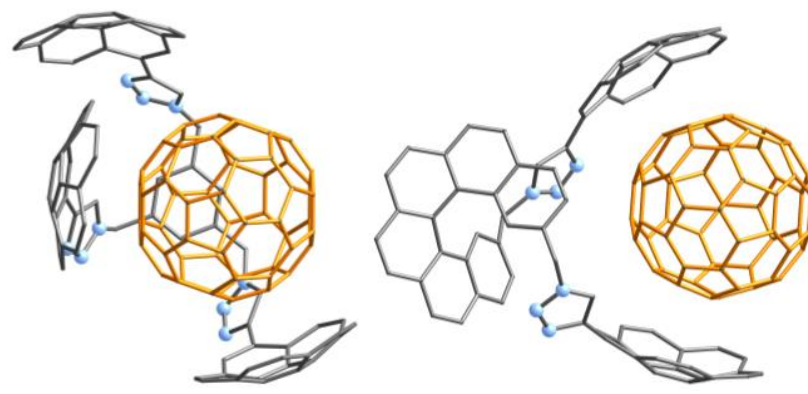

Figure 5. Optimized geometry for $\mathbf{2} \subset \mathbf{C}_{\mathbf{6 0}}$ and $\mathbf{3} \subset \mathbf{C}_{\mathbf{6 0}}$. Grey and orange bonds identify host and guest molecules, respectively.

The interaction energies between host molecules and the fullerene have been calculated in the optimized adducts and the results are gathered in Table 1 . The value for $3 \subset C_{60}(-44.26$ $\mathrm{kcal} / \mathrm{mol}$ ) is near twice as much as those formed by $\mathrm{C}_{60}$ and a single penta-substituted corannulene reported by RodríguezOtero et al $(\approx-22 \mathrm{kcal} / \mathrm{mol}),{ }^{17}$ and very similar to that obtained by Sygula and coworkers in their buckycatcher (-43.1 $\mathrm{kcal} / \mathrm{mol})^{5 \mathrm{e}}$. This expected result confirms that both corannulene subunits contribute equally to stabilize this adduct. However, if $\mathbf{2} \subset \mathbf{C}_{\mathbf{6 0}}$ is taken into account, the value is not tripled at all. The optimized structure shows one corannulene interacting with another via $\mathrm{CH}-\pi$ contacts (see Figure 5 , left), and, therefore, $E_{I N T}(-54.87 \mathrm{kcal} / \mathrm{mol})$ shows the contribution of two corannulene- $\mathrm{C}_{60} \pi-\pi$ interactions plus the latter $\mathrm{CH}-\pi$ contacts.

Nevertheless, we have calculated an adduct having a fullerene and three unsubstituted corannulenes well adapted to the geodesic polyarene surface, in which the $E_{I N T}(-53.05 \mathrm{kcal} / \mathrm{mol})$ is three times the value of the interaction between an unsubstituted corannulene and the $\mathrm{C}_{60}(-17 \mathrm{kcal} / \mathrm{mol}) .{ }^{17}$ This result is in agreement with the fact that the major contribution to the interaction energy is the $\pi-\pi$ interaction between a corannulene and a $\mathrm{C}_{60}$. Since in our host with three corannulenes (compound 2) the spacer is not long enough to allow the three corannulenes to interact with $\mathrm{C}_{60}$, an association constant similar to that of the host with only two corannulenes (compound 3) was obtained.

Table 1. Interaction energies ( $\mathrm{kcal} / \mathrm{mol})$ for all calculated adducts.

$\begin{array}{ll}\text { adducts } & \mathrm{E}_{\mathrm{INT}}{ }^{\mathrm{a}} \\ \mathbf{2} \subset \mathrm{C}_{60} & -54.87 \\ \mathbf{3} \subset \mathrm{C}_{60} & -44.26 \\ \mathrm{Cor}_{3} \subset \mathrm{C}_{60}{ }^{b} & -53.05\end{array}$


${ }^{a}$ Interaction energy (BSSE corrected). ${ }^{b}$ This adduct is formed by 3 corannulene molecules around $\mathrm{C}_{60}$.

In conclusion, we have designed and synthesized a family of fullerene receptors through a combination of several corannulene fragments linked by triazole units. It was found that $\mathbf{1}$ and 2 have remarkable association constants with fullerene $C_{60}$. $\left(\mathrm{K}_{\mathrm{a}}=(2.15 \pm 0.30) \times 10^{3} \mathrm{M}^{-1}\right.$ and $(2.19 \pm 0.05) \times 10^{3} \mathrm{M}^{-1}$, respectively). Although the use of a longer spacer that permits the interaction of all corannulene subunits with fullerene could be a reasonable decision in order to make the association constants larger, the potential entropy association penalty or solvation contributions could dramatically decrease the affinity toward fullerenes due to their larger flexibility. We have also developed a novel biscorannulene receptor $\mathbf{3}$, which bears a chiral hexahelicene moiety, with significant abilities for binding $\mathrm{C}_{60}\left(\mathrm{~K}_{\mathrm{a}}=(2.55 \pm 0.14) \times 10^{3} \mathrm{M}^{-1}\right)$. These findings open the possibility of utilizing the enantiomers of derivative $\mathbf{3}$, as host molecules for recognizing and discriminating higher chiral fullerenes. This potential application in enantioselective molecular recognition is currently under investigation.

\section{ASSOCIATED CONTENT}

\section{Supporting Information}

Synthetic procedure, NMR and MS spectra for 2,15bis(azidomethyl)-hexahelicene (9) and 1-3 compounds $\left({ }^{1} \mathrm{H}\right.$, ${ }^{13} \mathrm{C}\left\{{ }^{1} \mathrm{H}\right\},{ }^{1} \mathrm{H}-{ }^{1} \mathrm{H}$ COSY, ${ }^{1} \mathrm{H}_{-}{ }^{13} \mathrm{C}$ HSQC and ${ }^{1} \mathrm{H}-{ }^{1} \mathrm{H}$ NOESY), complexation studies and DFT calculations. This material is available free of charge via the Internet at http://pubs.acs.org.

\section{AUTHOR INFORMATION}

\section{Corresponding Author}

*(C.M.A.) E-mail: celedonio.alvarez@uva.es

\section{Notes}

The authors declare no competing financial interest.

\section{ACKNOWLEDGMENT}

This research was supported by the Spanish MINECO (Project CTQ2013-41067-P). H. B. wishes to thank for a MEC-FPI grant, and L. A. G.-E. thanks University of Valladolid for a Ph D grant. Allocation of computer facilities at IQTCUB is also acknowledged.

\section{REFERENCES}

(1) For reviews, see: Wu, Y.-T.; Siegel, J. S. Chem. Rev. 2006, 106, 4843-4867. (b) Tsefrikas, V. M.; Scott, L. T. Chem. Rev. 2006, 106, $4868-4884$.

(2) (a) Sygula, A.; Folsom, H. E.; Sygula, R.; Abdourazak, A. H.; Marcinow, Z.; Fronczek, F. R.; Rabideau, P. W. J. Chem. Soc., Chem. Commun. 1994, 2571-2572. (b) Lovas, F. J.; McMahon, R. J.; Grabow, J.-U.; Schnell, M.; Mack, J.; Scott, L. T.; Kuczkowski, R. L. J. Am. Chem. Soc. 2005, 127, 4345-4349. (c) Wu, Y.-T.; Hayama, T.; Baldrige, K. K.; Linden, A.; Siegel, J. S. J. Am. Chem. Soc. 2006 , 128, 6870-6884. (d) Wu, Y.-T.; Bandera, D.; Maag, R.; Linden, A.; Baldridge, K. K.; Siegel, J. S. J. Am. Chem. Soc. 2008, 130, 10729 10739. (e) Wu, Y.-T.; Siegel, J. S. Top. Curr. Chem. 2014, 349, 63120.

(3) Scott, L. T.; Hashemi, M. M.; Bratcher, M. S. J. Am. Chem. Soc. 1992, 114, 1920-1921.
(4) Dawe, L. N.; AlHujran, T. A.; Tran, H.-A.; Mercer, J. I.; Jackson, E. J.; Scott, L. S.; Georghiou, P. E. Chem. Commum. 2012, 48, 5563-5565.

(5) (a) Mizyed, S.; Geourghiou, P. E.; Bancu, M.; Cuadra, B.; Rai, A. K.; Cheng, P.; Scott, L. T. J. Am. Chem. Soc. 2001, 123, 1277012774. (b) Sygula, A.; Sygula, R.; Ellern, A.; Rabideau, P. W. Org. Lett. 2003, 5, 2595-2597. (c) Georghiou, P. E.; Tran, A. H.; Mizyed, S.; Bancu, M.; Scott, L. T. J. Org. Chem. 2005, 70, 6158-6163. (d) Sygula, A.; Fronczek, F. R.; Sygula, R.; Rabideau, P. W.; Olmstead, M. M. J. Am. Chem. Soc. 2007, 129, 3842-3843. (e) MückLichtenfeld, C.; Grimme, S.; Kobryn, L.; Sygula, A. Phys. Chem. Chem. Phys. 2010, 12, 7091-7097. (f) Yanney, M.; Sygula, A.; Tetrahedron Lett. 2013, 54, 2604-2607. (g) Le, V. H.; Yanney, M.; McGuire, M.; Sygula, A.; Lewis, E. A. J. Phys. Chem. B 2014, 118, 11956-11964. (h) Sygula, A.; Yanney, M.; Henry, W. P.; Fronczek, F. R.; Zabula, A. V.; Petrukhina, M. A. Cryst. Growth Des. 2014, 14, 2633-2639.

(6) (a) Stuparu, M. C., J. Polym. Sci. Part A Polym. Chem. 2012, 50, 2641-2649. (b) Stuparu, M. C., Angew. Chem. Int. Ed. 2013, 52, 7786-7790.

(7) Álvarez, C. M.; García-Escudero, L. A.; García-Rodriguez, R.; Martin-Álvarez, J. M.; Miguel, D.; Rayón, V. M. Dalton Trans. 2014, 43, (42), 15693-15696.

(8) Huerta, E.; Isla, H.; Pérez, E. M.; Bo, C.; Martín, N.; de Mendoza, J. J. Am. Chem. Soc. 2010, 132, 5351-5353.

(9) Lahann J. Click Chemistry for Biotechnology and Materials Science Wiley-VCH Michigan, Ann Arbor, USA 2009.

(10) Stuparu, M. C. Tetrahedron 2012, 68, 3527-3531.

(11) For synthesis of ethynylcorannulene (4) see: Mack, J.; Vogel, P.; Jones, D.; Kaval, N.; Sutton A. Org. Biomol. Chem., 2007, 5, 2448-2452.

(12) For synthesis of $\alpha, \alpha, \alpha$-tris(azidomethyl)ethane (5) see: (a) Beaufort, L.; Delaude, L.; Noels A.F. Tetrahedron 2007, 63, 70037007. For synthesis of 1,3,5-tris(azidomethylbencene) (6) see: (b) Granzhan, A.; Schouwey, C.; Riis-Johannessen, T.; Scopelliti, R.; Severin, K. J. Am. Chem. Soc. 2011, 133, 7106-7115.

(13 ) (a) Mallory, F. B.; Mallory, C. W. Photocyclization of stilbenes and related molecules. Organic Reactions; Wiley: Hoboken, NJ, 1984; Vol. 30, 1-456. (b) Yamamoto, K.; Sonobe, H.; Matsubara, H.; Sato, M.; Okamoto, S.; Kitaura, K. Angew. Chem., Int. Ed. 1996, 35, 69-70. (c) Sato, M.; Yamamoto, K.; Sonobe, H.; Yano, K.; Matsubara, H.; Fujita, H.; Sugimoto, T.; Yamamoto, K. J. Chem. Soc., Perkin Trans. 2 1998, 1909-1913.

(14) Suezawa, H.; Yoshida, T.; Ishihara, S.; Umezawa, Y.; Nishio, M. CrystEngComm. 2003, 5, 514-518.

(15) (a) Miyajima, D.; Tashiro, K.; Araoka, F.; Takezoe, H.; Kim, J.; Kato, K.; Takata, M.; Aida, T. J. Am. Chem. Soc. 2009, 131, 4445. (b) Schmidt, B. M.; Topolinski, B.; Roesch, P.; Lentz D. Chem. Commun. 2012 ,48, 6520-6522.

(16) See Supporting Information for details about the methodology for computational studies and previous studies carried out.

(17) Josa, D.; Rodríguez-Otero, J.; Cabaleiro-Lago, E. M.; Santos, L. A.; Ramalho, T. C., J. Phys. Chem. A 2014, 118, 9521-9528. 